\title{
Unconscious Belief and Conscious Thought ${ }^{1}$
}

Tim Crane

\section{Introduction}

We call our thoughts conscious, and we also say the same of our bodily sensations, perceptions and other sensory experiences. But thoughts and sensory experiences are very different phenomena, both from the point of view of their subject and in their functional or cognitive role. Does this mean, then, that there are very different kinds or varieties of consciousness? Philosophers do often talk about different kinds of consciousness: Christopher Hill, for example, claims that 'it is customary to distinguish five forms of consciousness' (Hill 2009: 1). These are: agent consciousness, propositional consciousness, introspective consciousness, relational consciousness and phenomenal consciousness; to which Hill adds experiential consciousness, making six in total.

It is an important question for the theory of consciousness whether these labels pick out genuinely different psychological phenomena, or whether some (or all) of them are just different ways of talking about the same thing. I cannot address this large question here, but I will instead focus on a more specific question: is the kind of consciousness involved in sensation an entirely different thing from the kind of consciousness involved in thought? Or is there a single kind of consciousness which both these kinds of mental phenomena exhibit, regardless of how else they might differ?

In this paper I will attempt to answer this question. Some dominant theories of consciousness give it quite unsatisfactory answers. I will consider three recent theories: that consciousness consists in the instantiation of a simple quality; that

\footnotetext{
${ }^{1}$ The ideas in this paper were first aired at an ESF-sponsored conference in Sardinia, as part of the EUROCORES 'Consciousness in its Natural and Cultural Context' (CNCC) initiative. I'm very grateful to Pierre Jacob, Barry C Smith and Till Vierkant for helpful discussion on that occasion, and to subsequent audiences at King's College London (Institute of Psychiatry, Philosophy Group), Oxford Brookes University and the University of Durham, the RIP conference in Edinburgh in honour of Timothy Sprigge, and the Conference in Liverpool on the work of Barry Dainton. Special thanks to Katalin Farkas and to an anonymous reader for OUP for their very useful suggestions; and thanks to Mike Martin and Matt Soteriou for discussion of these matters.
} 
consciousness consists in higher-order representation; and that there are two independent kinds of consciousness with wholly different natures (in this connection, I will consider Block's well-known distinction between 'phenomenal' and 'access' consciousness). None of these gives entirely the right answer, although the last comes closest.

I will argue for three claims: (1) that Block's notion of access consciousness must be understood in terms of phenomenal consciousness, and in this sense phenomenal consciousness is the more fundamental notion; (2) beliefs are never phenomenally conscious, though episodes of thinking are; (3) the sense in which thoughts and experiences are conscious is that they are both a certain kind of episode, that I call an episode in the stream of consciousness. This last claim provides the answer to the question posed above: there is a single kind of consciousness which thoughts and experiences exhibit.

I do not give a definition of what phenomenal consciousness is, nor a description of it in non-mental terms. Indeed, like many philosophers working in this area, I take the fact of consciousness for granted, and I do not believe that it can be reduced or 'defined'. Rather, I will attempt to outline some of the relationships between conscious thoughts, other conscious episodes, and unconscious mental states like beliefs, with the aim of getting a clear overview of aspects of the phenomenology of consciousness.

How do my claims connect to the currently popular idea of 'phenomenal intentionality'? The term 'phenomenal' has been understood in a number of ways in contemporary philosophy, but if we restrict it only by its etymology, then 'phenomenal' means pertaining to appearances. So phenomenal intentionality is intentionality that relates to how things appear - but 'appear' must mean 'consciously appear' if the term's current usage is to make any sense.

Conscious thought is the most crucial phenomenon for theories of phenomenal intentionality. All theories of consciousness recognize the existence of phenomenal consciousness in the sense I have just described (even if they do not use this term). Sensations and sensory experiences are the paradigm examples. Many theories hold in addition that such experiences have intentional content - that they represent states of the world or states of the subject. Intentionalist theories of consciousness are now widely accepted, even if they are not entirely uncontroversial. But just as intentionalist theories of consciousness are not news, the phenomenal intentionality 
they talk about - the intentionality of bodily sensation and perception - is not news either.

What is controversial is whether there is a distinctive kind of conscious or phenomenal intentionality associated with conscious thought (see e.g. Pitt 2004; Bayne and Montague 2011). This is not something which is implied by the very idea of an intentionalist theory of consciousness. It is possible to hold that all consciousness is intentional, or representational, without holding that conscious thinking has any distinctive phenomenology of its own. Michael Tye, for example, is a well-known defender of intentionalism about consciousness; but recently he has explicitly denied that thoughts have 'a further phenomenology over and above the imagistic and sensory phenomenology that may accompany conscious thoughts' (2009: 201). For Tye, there is only imagistic or sensory phenomenal consciousness; and since all consciousness is intentional, there is only imagistic or sensory phenomenal intentionality.

However, I am persuaded by the arguments of Kriegel (2007), Pitt (2004), Strawson (1995) and others that there is a distinctive kind of phenomenal intentionality associated with conscious thought: thought has a so-called 'proprietary phenomenology'. But I will not attempt to argue for this here. Rather, I am attempting something more modest: to sketch an account of the structure of conscious thinking, in order to make it intelligible how thought can be conscious in the same sense as sensations and sensory experiences.

In the next section, I will argue that two well-known theories of consciousness fail to give an adequate answer to the question of why thoughts and sensations are both conscious, and that Block's claim that 'conscious' is ambiguous also fails to answer this question in a satisfactory way. I will then argue in section 3 that my approach to Block's distinction also helps to illuminate what is sometimes called (I think misleadingly) conscious belief. In section 4 I show the bearing of these points about belief on the phenomenon of conscious thought, and hence on the thesis of phenomenal intentionality.

\section{Two inadequate answers to our question}

Some popular theories of consciousness, it seems to me, are unable to give a single account of the consciousness involved in thought and in sensation. One is the theory that consciousness involves the instantiation of intrinsic, non-intentional properties, 
known as 'qualia' (Block 1996). Another is the theory that consciousness is higherorder thought or representation: the 'HOT' theory of consciousness (Rosenthal 1986). While the qualia theory may have some plausibility for conscious sensations, it is hard to apply it to conscious thought. And while the HOT theory might make sense in the case of conscious thought, it has little plausibility when applied to sensation.

The qualia theory identifies consciousness with the instantiation of qualia: properties which are variously described as intrinsic, non-intentional, ineffable and private. The details of particular theories of qualia do not matter here, since my objection is quite general. The paradigms of qualia are bodily sensation properties, like the property of being in pain, or perhaps some specific properties of pain states or events. Sensory qualities like this have a particular 'feel' which is essential to them. To each distinctive type of quale corresponds a distinctive sensory 'feel'.

Conscious thought cannot plausibly be described in this way. If you are currently thinking about the causes of the current financial crisis, there is no particular sensory feel that this episode has. In fact, it sounds strange to talk of this episode as having any 'feel' at all. If it feels like anything to be thinking about the financial crisis, this kind of 'feeling' has so little in common with sensory feelings that it is unilluminating to describe them both as having qualia. If we are inclined to say that thinking 'feels like' something, then all we can really mean by this is that it is conscious. But this is what we are trying to understand, so it is hardly an explanation to say that there are 'feelings' in this sense associated with thinking, or that thinking involves qualia.

The HOT theory might appear to fare better in accounting for conscious thought. On this theory, a mental state's being conscious is a matter of its being the object of a higher-order thought or other representation. Theories differ as to whether the higher-order state actually has to be instantiated or whether one needs only to have the capacity or disposition to have these higher-order representations (for the latter view, see Carruthers 2003). But again, the details do not really matter here, since my question is the general one of whether such a view can possibly apply both to conscious thought and to conscious sensation.

In the case of thought, it might seem a plausible approach: what it is to have a conscious thought is to be conscious of your thought, and what is being conscious of a thought other than representing it? (Lycan 2001 uses this point as part of his 'simple 
argument' for a higher-order theory of consciousness.) The point is not indisputable, but it has something to be said for it. (In $\S 4$ below I will dispute it.)

Yet in the case of sensation, being conscious of a sensation cannot be understood simply in terms of representing it. We can envisage creatures who are incapable of thought about their mental states but nonetheless can feel sensation surely many animals are actually like this. And even in our own case, the consciousness of a sensation is plausibly something which is internal to the sensation itself, rather than a product of thought or representation of it. 'Conscious of' does not always mean 'representing'. Being conscious of a pain in one's toe - in the sense of being aware of it when you have it - is a different thing from being conscious of the pain when you think about it and attend to it. Merely having the pain, in normal cases, is sufficient for awareness of it.

One way to respond to the inadequacies of these two theories is to say that each is right in its own way - the qualia theory is on the right lines when it comes to conscious sensation, while the higher-order thought theory is on the right lines when it comes to conscious thought. This is either because 'consciousness' is ambiguous, or because there are two (or more) kinds of consciousness; or these might be two ways of saying the same thing. I will briefly examine the best-known version of this proposal: Ned Block's distinction between phenomenal and access consciousness.

In his original (1995) presentation of the distinction, Block said that "consciousness" is an ambiguous word, though the ambiguity I have in mind is not one I've found in any dictionary' (Block 1995: 391). Phenomenal consciousness he defines in a usual way as 'experience: what makes a state phenomenally conscious is that there is something "it is like" to be in that state' (Block 1995: 380). Access consciousness is defined for representations, and in terms of these representations' role in reasoning and control of action: 'a representation is access-conscious if it is poised for free use in reasoning and for direct "rational" control of action and speech' (1995: 382). In later writings on this subject (e.g. Block 2002), Block modified his presentation somewhat, to answer criticism suggested by his choice of terminology. To indicate that he is using the words in a more technical sense, he called phenomenal consciousness 'P-consciousness' and access consciousness 'A-consciousness'. For Block, sensations are the paradigms of P-conscious states, while propositional attitudes (e.g. belief) are the paradigms of A-conscious states (2002: 281). 
Could this be the answer to my question, then: that sensations are phenomenally $(\mathrm{P})$ conscious, and thoughts are merely access (A) conscious? On the face of it, the answer seems to be no, for two reasons. First, thoughts can be phenomenally conscious too, as we noted above, in a perfectly ordinary sense of 'phenomenal'. When consciously thinking about something, things can appear to you a certain way - you might be imagining something, reflecting on it intellectually, or preoccupied by memories of it. But all these cases involve the appearance of things in the world, and (as we noted above) this is the original meaning of 'phenomenal'. It is , of course, common these days to use the word 'phenomenal' to apply only to sensory consciousness. But even if one were to restrict the word in this way, visual imagination still counts as thinking, even though it involves sensory 'phenomenal' qualities. So if visually imagining can be a kind of thinking, then some thinking can be phenomenally conscious, in the broader or narrower sense of that word.

The second reason why Block's distinction cannot be straightforwardly used for answering our question is that sensations themselves can be available to reasoning systems; they are accessible for verbal report; they are available to memory, and so on. So sensations can be A-conscious too. It might be said that sensations are not representations, so by definition are not A-conscious states. But it is not obvious that sensations are not representations: representationalists or intentionalists explicitly claim that they are (see Tye 1995; Crane 2001). Such representationalism may be false, but it is not obviously false.

Block's distinction does not provide a clear and simple answer to our question. The distinction (between being conscious as such and 'accessing' one's conscious states) is certainly something real, but I am skeptical of the way he tries to distinguish one from the other as independent phenomena, or distinct existences, by showing how they can be dissociated. The reason for my skepticism is that although there clearly is such a thing as 'accessing' one's states of mind, this cannot be fundamentally understood independently of the idea of phenomenal consciousness. I will now argue for this claim.

When Block originally introduced the notion of access consciousness, he introduced it in term of the notion of being 'poised' for control of action and speech. 'Poised' in this sense is a dispositional notion - I can be poised to dive into the swimming pool even if I do not actually do it. In this respect it is like the ordinary notion of 'access': I can have access to the money in my bank account even if I am 
not actually 'accessing' it. Yet as Block later acknowledged, a dispositional notion is not what is needed here since consciousness is an occurrence (2002: 279). So he revised his definition of A-consciousness by saying that a representation is Aconscious if it is broadcast for free use in reasoning and so on (2002: 278).

Broadcasting seems to be an event-like thing, or a process, and hence something occurrent. (I will return to occurrences in $\S \S 3-4$.)

But when Block spells out what 'broadcast' literally means, he appeals once again to dispositional ideas. At one point he glosses 'broadcast' in terms of the senses 'making available' representations to other 'consuming systems', such as systems of classification, memory and so on (2002: 278). But what if these representations are made available to other systems and these systems never take advantage of their availability? Are they still conscious in any ordinary sense? Block also says that an element in A-consciousness is 'reportability' (2002: 278). But, again, what if these representations are reportable and no-one actually reports on them? Are they still conscious?

I don't think it is particularly helpful here to identify A-consciousness with information-processing, as Block does. It's not just that there is nothing in the idea of processing information which requires that it be conscious (although this is true). It's rather that all the paradigm examples of cognitive information-processing which we have are examples of things that take place unconsciously. Block may say that this is to use the word 'conscious' in the phenomenal sense. But the difficulty is that everyone will agree that much of our psychological information-processing is unconscious. What is it, then, that distinguishes the A-conscious informationprocessing from the unconscious?

Block is sensitive to the criticism that a creature who only had Aconsciousness in his sense would (in some intuitive sense) be an unconscious creature, but nonetheless insists that it is worth calling A-consciousness a kind of consciousness. As he points out, the access-related notion is the notion used in some psychoanalytic discourse - when one has an unconscious desire in something like the Freudian sense, it is one that one cannot access. And the notion of consciousness as accessibility or reportability is also used in much psychology and cognitive neuroscience. These are his reasons for insisting that if a creature were purely Aconscious, it would still be conscious in an ordinary sense. But he concedes that 'A- 
consciousness can be a kind of consciousness even if it is parasitic on a core notion of P-consciousness' (2002: 282).

I think Block is quite right to make this concession. But how should we spell out the idea that A-consciousness is parasitic on P-consciousness? I think the connection is simpler than Block says. The idea that there is an interesting category of states which we can access is (in general) quite true. And we should understand access in terms of availability to other processes and cognitive systems in the way Block says. Assuming that accessing something is bringing something about, then we can ask: what kind of thing is brought about? The obvious answer is: a phenomenally conscious occurrence. To access or 'broadcast' a mental state is to bring about a change in phenomenal consciousness. So understood, accessing our mental states is not a special kind of consciousness, but rather a matter of bringing those mental states to phenomenal consciousness. This understanding of 'access' (or 'broadcasting') presupposes phenomenal consciousness.

However, it does not follow from the fact that some essentially non-conscious state $\mathrm{S}$ brings about a change in phenomenal consciousness that $\mathrm{S}$ itself is made conscious. Many states or events in the brain bring about changes in phenomenal consciousness without being conscious in any way whatsoever. The important thing is not just that the state brings about the change in phenomenal consciousness but that the state itself 'figures' (in some sense) in consciousness. And since mental states are individuated by their contents, what is important about the state itself 'figuring' here is its content. Consciously accessing your belief that Mongolia had the second largest empire in the history of the world implies that this content is brought to phenomenal consciousness, since that is what distinguishes that belief from all others.

So to bring a state of mind to phenomenal consciousness is (at the very least) to bring its content to consciousness: that is, to bring about an event in phenomenal consciousness in which that content figures. The next question, then is this: what is it to bring the content of some mental state to phenomenal consciousness. I will discuss this question in $\S 4$. But before doing this, I will explain how my way of understanding Block's distinction makes sense of what is sometimes called 'conscious belief'. 


\section{3. 'Occurrent' and 'conscious' belief}

It is frequently said that there is a distinction between beliefs which are conscious and those which are unconscious. Some go further: Christopher Peacocke has attempted to define the concept of belief partly in terms of the idea of conscious belief:

A relational conception $R$ is that of belief only if the following condition is met:

(F) The thinker finds the first-person content that he stands in $R$ to the content $p$ primitively compelling whenever he has the conscious belief that $p$, and he finds it compelling because he has that conscious belief. (Peacocke 1993: 163)

For Peacocke's definition to be intelligible, there must be an intelligible distinction between conscious and unconscious belief. But what is this distinction?

Some theories attempt to explain the distinction in terms of lower-order versus higher-order attitudes: D.H. Mellor, for example, has argued that a conscious belief in a proposition is simply the belief that one believes it (1977: 90). Mellor's proposal resembles the higher-order thought theory defended by Rosenthal (1986). But unlike Rosenthal, he does not think it is the correct account of all forms of consciousness. Others explain conscious belief in terms of the idea of an 'occurrent' belief, which is distinguished from 'dispositional' belief. Here I will focus on this latter thesis: that conscious belief is occurrent belief. When we identify what is wrong with this thesis, it will show us what is wrong with the idea of conscious belief as higher-order belief.

The reasons for taking beliefs to be dispositions - to combine with other mental states to cause actions or other mental occurrences - are well known, and I will not dwell on them here. ${ }^{2}$ Belief understood as a disposition is sometimes contrasted with occurrent belief, usually in order to identify and describe the phenomenon of 'conscious belief'. Uriah Kriegel, for example, argues that we should 'construe a conscious belief as one that is at once an occurrent first-order belief and an occurrent second-order belief' (Kriegel 2004: 108; see also BonJour 1999: 131). Kriegel implies that the distinction between first- and second-order beliefs is not sufficient to pick out the conscious beliefs: the beliefs must be occurrent too.

An occurrent belief is presumably supposed to be a kind of occurrence: that is, an event or episode. A disposition is a different kind of thing: a state or property,

\footnotetext{
${ }^{2}$ A distinction is sometimes made between dispositional belief and a disposition to believe (see, e.g., Audi 1994). This is a useful distinction but it is not directly relevant to what I want to argue here.
} 
something that persists beyond its manifestations (which are themselves occurrences). So an occurrent belief cannot be the very same thing as a dispositional belief, any more than a breaking can be the very same thing as an instance of fragility (pace Gennaro 1996: 41). It cannot be right to say that the very same belief state is both conscious and unconscious, if 'conscious belief' is understood as occurrent belief. What must be meant (at least) by saying that a conscious belief is the same as an unconscious belief is that it has the same content: these are states in which you believe the same thing (i.e. the same proposition). But the state also needs to involve accepting or endorsing that content, if it is to be anything like a belief. As Laurence BonJour puts it, 'what one is primarily conscious of in having such a belief is precisely its propositional content (together with one's acceptance of that content)' (BonJour 1999: 131).

There can be no objection in principle to the idea that mental phenomena of different types may have the same content. You can hope that the weather will improve, and you can believe that the weather can improve. But hope and belief are unquestionably different mental phenomena. More controversial, but still widely endorsed, is John McDowell's well-known claim that the content of a perceptual experience can also be the content of a judgement (1994: 9$)^{3}$. So there cannot be a general objection to the idea of conscious and unconscious beliefs having the same content.

However, in cases like these, the states are different because what (we can call) their 'attitudinal' components are different: belief, hope, perception or judgement. But occurrent and dispositional belief are both supposed to be kinds of belief. So they must both have some or all of the distinguishing marks of belief. But it hard to see how whatever occurrence it is that is being labeled by the words 'occurrent belief' can have these distinguishing marks.

The essence of belief, I take it, is that it is taking something to be the case. We could also say that a belief is taking something to be true, so long as this does not imply that in order to have beliefs, a believer must have the concept of truth. This is a more controversial thesis, and should not be built into the minimal idea of belief which all should accept. Likewise, a believer (in this minimal sense) need not have the concept of something's being the case. In this sense, a relatively simple creature

\footnotetext{
${ }^{3}$ This is a claim McDowell went on to reject: see his 2009.
} 
can have beliefs, so long as it takes the world to be a certain way, or takes certain things to be the case.

'Taking something to be the case' could be understood in terms of perceptual consciousness, where what is taken to the case is present to the mind at the moment it is perceived. But this is not how it is with belief: belief is not just a matter of taking something to be the case for the duration of (e.g.) a perceptual experience. Rather, it is essential to beliefs that they persist through changes of in current consciousness. Beliefs are stored in memory and can be called upon when future action is needed. It is crucial that they do this if they are to guide the actions of organisms in the way they do. An organism which could only take things to be the case as they perceptually seem at the present moment would have to learn anew each fact about its environment. It's hard to know whether there are any such creatures, but it is clear enough that we and other believers are not like this.

When a belief is formed, by perception or by other means, it can be stored in the organism's mind and then can be put at the service of the organism's projects in various ways - either by guiding action, by being used in reasoning or by being used in planning. For beliefs to play this functional role, they must continue to exist - that is, persist - beyond the moment of their acquisition.

This feature of beliefs is reflected in our commonsense psychological understanding: we do not count someone as stopping believing something when they go to sleep, lose consciousnesss, or when the subject-matter of their belief is not before their conscious mind. A defender of 'conscious beliefs' must say that this is one of the reasons that we should recognize the phenomenon of unconscious belief: in descriptions of this phenomenon, we are typically invited to think of all the things which we believe which have rarely, if ever, come before our conscious mind. This is quite right - but it is rarely recognized that since the persisting character of belief is essential to it, it makes conscious belief hard to understand.

If a conscious belief were an occurrence, it would exist for as long as that occurrence were to exist. For a belief to cease to be conscious, then, on this understanding, would be for the occurrence to cease, or to go out of existence. But if the occurrence thus went out of existence - for example, when the subject paid attention to something else, or became unconscious - then it cannot play the essential role of belief as I have characterized it. So whatever such an occurrence is, it cannot be belief: 'occurrent belief' is not belief at all. 
It might be objected that this is a merely verbal point: that all I am doing here is deciding to use the word 'belief' for the persisting, unconscious functional state, and forbidding its use for occurrent, conscious episodes of judgement. But since I do not deny that that there are such conscious episodes, then what can be wrong with calling them 'beliefs', so long as we also distinguish episodes from persisting states?

It is, of course, notoriously difficult to say when a thesis or question is a 'merely verbal' one. But if I am right that there is a fundamental metaphysical distinction between episodes/occurrences and persisting states, then it is misleading at best to use the term 'belief' for entities in both categories. For one kind of entity goes out of existence when we go to sleep and another does not. How much more different could these entities be? Calling these two states 'belief1' and 'belief2' would only obscure the fundamental difference between them.

Some support for this view of belief - that conscious belief is not a kind of belief - comes from reflection on the phenomenon of knowledge. Although on most views, there is a close connection between belief and knowledge, it is not common to hear talk of 'conscious knowledge', as there is this tendency to talk of conscious belief. And no-one talks of 'occurrent' knowledge. ${ }^{4}$ This is revealing: for if belief can be occurrent, why can knowledge not be so too? And yet knowledge often plays the same kind of functional role as is often attributed to belief, in organizing an subject's behaviour and reasoning (see Williamson 2000: 60-4). And we do not consider that someone necessarily loses their knowledge when they go to sleep. Knowledge can be lost, of course: there is forgetting, and there are maybe other ways of losing knowledge too (see Dretske and Yourgrau 1983). But someone does not lose knowledge in any sense simply because they think about something else, or lose consciousness. So for the same kinds of reason why belief cannot be an occurrence, knowledge cannot be an occurrence either.

What is undeniable is that there is such a thing as bringing what you know to mind, or to consciousness. Bringing $X$ to mind is without question an occurrence; but this fact on its own does not make 'bringing $X$ to mind' a special kind of $X$. One could stipulate here, and say that all that is meant by calling a belief 'occurrent' is that it is one which you are bringing to mind, or bringing to consciousness, or consciously

\footnotetext{
${ }^{4}$ We should ignore here Russell's (1910-11) notion of 'knowledge by acquaintance', which is supposed to be an occurrent mental act. It is arguable how much it has to do with the ordinary concept of knowledge: see Crane 2011.
} 
attending to. This is how I understand a remark like this of Graham Oddie's: 'a belief is occurrent if it is the belief that you are consciously attending to' (Oddie 2005: 240). Whatever the merits of such a stipulation, it clearly isn't supposed to be part of an explanation of consciousness, since it assumes the idea of 'consciously attending' to something. This is not an objection to the stipulation as such; it is just to point out what the stipulation is, and is not, supposed to be doing.

Nonetheless, whatever stipulations we make, we should accept that there is such a thing as attending to what we know and believe. 'Bringing what we believe to consciousness' is a good description of this, however this notion should be further understood. ${ }^{5}$ And it is plausible that this is the same phenomenon as the phenomenon Block calls 'A-consciousness'. I argued above that we should understand Block's notion of A-consciousness in terms of bringing about a phenomenally conscious episode. That is, a state is A-conscious when it is accessible to consciousness, where this is understood in terms of being available to figure in an episode or occurrence in phenomenal consciousness. This is also how I think we should understand the talk of conscious belief.

As I argued in the previous section, we should not say that A-consciousness is a distinct sort of consciousness simply because it is a disposition to bring about events in phenomenal consciousness. And the same applies to the idea of 'conscious belief'. Just as, on Block's view, a representation is 'A-conscious' when it can be brought to phenomenal consciousness, so a belief is 'conscious' or 'occurrent' when it can be brought to phenomenal consciousness. 'Occurrent' in 'occurrent belief' is a sort of transferred epithet: what is conscious is not the belief itself, but the episode of being conscious of that belief.

It is important to emphasise that bringing a belief to consciousness is not just a matter of being aware of its content - since, as we saw above, the same content can be the content of many different kinds of mental state. When a belief is brought to phenomenal consciousness, the 'attitudinal component' (what in other work (2001) I have called, following Searle (1992), the 'intentional mode') must also be an object of phenomenal consciousness

\footnotetext{
${ }^{5}$ David-Hillel Ruben remarks, of the term 'occurrent belief' that 'I know of no plausible characterisation of what is intended by this term, except the one that ties it to present awareness or consciousness' (Ruben 2003: 114); and he further writes that 'many, like Alvin Goldman, thought of "occurrent" as I do, as elliptical for "occurrent to present consciousness"” (Ruben 2003: 116).
} 
So my understanding of 'bringing something to consciousness' is the same as my understanding of A-consciousness: what is conscious, first and foremost, is an event, not a persisting state. If this is right, then this tells against those accounts of 'conscious belief' (like Mellor's and Rosenthal's) which attempt to explain the consciousness of a belief in terms of the existence of a certain kind of state (i.e. a higher-order belief). For all belief states must have the essential characteristic of beliefs: namely, they must persist through changes in consciousness, or even through the absence of consciousness. But if this is an essential characteristic of all belief states, it will be possessed by higher-order belief states as well. So higher-order belief states cannot be conscious episodes.

\section{Thought and the stream of consciousness}

In §2 I argued that what Block calls A-consciousness should not really be thought of as a different kind of consciousness, distinct from phenomenal consciousness. Rather, to call a state 'A-conscious' is to say that it can give rise to phenomenally conscious episodes. I then applied the same idea to the distinction between conscious and unconscious belief. What are called 'conscious beliefs' are not really beliefs at all, but rather phenomenally conscious episodes: episodes of being aware of what you believe and the fact that you believe it. The belief state itself is not conscious; rather, you can be conscious of what you believe when such a phenomenally conscious episode occurs.

So when we call persisting mental states 'conscious' what we really mean is that they can give rise to a certain kind of phenomenally conscious events. It follows that when Block talks of A-conscious states, he should be interpreted as talking about states which can give rise to - or manifest themselves in - certain phenomenally conscious events, or what can be called more generally 'occurrences'.

What the philosophy of consciousness needs, then, is the distinction between occurrences and persisting states. ${ }^{6}$ Events and processes are both occurrences: they take time, they can unfold over time and have temporal parts. My watching a bird catching a worm in the garden is an event, as is the event I am watching. Both events take time, they unfold or develop over time, they typically consist of earlier parts or periods. Maybe there are also instantaneous events; in which case, not all events have

\footnotetext{
${ }^{6} \mathrm{I}$ am indebted here to discussions with Mike Martin and Matt Soteriou: see Soteriou 2007.
} 
significant temporal parts. But nonetheless, an instantaneous event is still an occurrence: something that happens.

States do not unfold or evolve over time: they consist in the instantiation of properties and/or relations in objects. If we think of an object as changing its state e.g. its temperature - this is not because the state itself evolves over time, but because one state is followed by a different one. This is because states do not have temporal parts. My having the height I do is a state of me; it makes no sense to talk about the earlier part or the later part of my having the height I do.

D.H. Mellor once distinguished between objects and events by saying that unlike events, objects are 'wholly present' at each moment of their existence (1981: 104). This distinction can be used also to distinguish between events and states. An event with temporal parts cannot be wholly present throughout each moment of its existence: at any moment at which the event is 'going on' or happening, some temporal parts of the event exist or are present, and others do not. This is not true with states. Consider a state which consists in an instantiation of a property in a particular over a period of time (note that I am not saying that all states have this structure; this is just an example). The property and the particular are wholly present at each moment of the state's existence or instantiation. If the particular ceases to have this property, then it undergoes a change of state. The change itself is an occurrence, but the resulting state is not.

It is the distinction between occurrences and states which gives the nonmetaphorical backbone to William James's famous image of a stream of consciousness:

Consciousness, then, does not appear to itself chopped up in bits. Such words as 'chain' or 'train' do not describe it fitly as it presents itself in the first instant. It is nothing jointed: it flows. A 'river' or a 'stream' are the metaphors by which it is most naturally described. In talking of it hereafter, let is call it the stream of thought, of consciousness, or of subjective life. (James 1890: 233)

The image of a stream flowing suggests motion, and one thing following another. But 'following' in the case of consciousness must mean following in time. Events follow one other in time; objects do not (see Davidson 1967: 691). A cat can literally follow 
a mouse in space (e.g. around a room), but the event of the cat's eating the mouse 'follows' the event of the cat's catching the mouse only in its temporal ordering.

Of course, states too can be ordered in time, since they are defined in terms of objects, properties and times. States can be ordered as their constituent times are ordered: as earlier than, later than or simultaneous with others. For some philosophers, this shows that all we need is the notion of a state, and no independent notion of an event. (Alternatively, they might, like Lewis (1986) and Kim (1976) use the word 'event' for what I am calling states.)

I cannot here show that such a reductionist view of events - a reduction of events to what I would call 'states' - is incorrect. All I will assume here is that the distinction is phenomenologically plausible for the reason James says: a sequence of states is something more like a train or a chain than something flowing, and conscious processes do not seem like chains or trains. Of course, this phenomenological observation is not decisive: it could be said that what appears to be continuous and flowing at the phenomenological level might be constituted by states which are discrete at the level of the underlying reality (just as a film in the cinema might represent continuous motion, despite the fact that it is made up of many discrete images shown one after another).

Here though, my concern is with consciousness, with the phenomenal, with the apparent metaphysics of how things seem; and not with the fundamental metaphysics. The distinction between the state of something - (e.g. the shape of the tree outside my window) and an event (e.g. the woodpecker pecking against its bark) - is a distinction which it is easy to appreciate from within consciousness. Whether the fundamental reality of the universe is event- or state-like is a further question.

In $\S \S 2-3$ I argued that we should think of A-conscious states (for example, socalled conscious beliefs) as states which could be 'brought' to phenomenal consciousness. But what does it mean to 'bring' a state to phenomenal consciousness? One answer is clear: it is not to create another, conscious, version of the state itself. What is brought to mind when reflecting consciously on one's beliefs is not itself another belief. My claim is that what is brought to mind is, rather, a conscious thought.

A conscious thought is an episode of thinking something. 'Thought' here refers to the episode or 'act' of thinking, not to what is thought (the latter is a proposition, or a Gedanke in Frege's terminology). Thoughts in the sense in which I 
use the word form a heterogeneous category: I include episodes of speculation, wondering, imagining, planning, as well as the central phenomenon of judgement.

There are three broad kinds of conscious occurrence which can be called judgement. The first kind occurs when a subject is making up their mind about something. When they have not formed a belief about some subject-matter and need to do so, they may weigh up the evidence and come to one conclusion or other; or they may 'suspend judgement'. Here judgement is the formation (or the attempted formation) of belief. Judgement stands to belief in this case as decision stands to intention. Just as a conscious judgement is (in this kind of case) an event which is the formation of a belief, so a conscious decision is an event which is the formation of an intention. Intentions, like beliefs, are persisting states, and like beliefs they can manifest themselves in consciousness. (Another similarity is that one can take oneself to have formed a belief, and yet future circumstances show that one did not really have this belief; the same can be true of intention.)

Episodes of the second kind of judgement are those which occur when our beliefs are brought to mind without effort, or any act of will. We need our beliefs to guide our action in the world, and often this needs to be conscious. Or we reveal what we believe in consciousness when someone asks us a question, and the answer occurs to us immediately, without effort or without having to make up one's mind.

The third kind of case occurs when one deliberates explicitly in consciousness about what one already believes. This can occur when one is trying to work out what one believes, or remember some fact, or draw out some consequence of what one believes. As with the second kind of case, this isn't a case of forming a belief, but rather a case of revealing to oneself what one believes anyway. But this case involves effort, and what is sometimes called introspection.

In contemporary terminology, occurrences of all three kinds are manifestations of our capacity for 'self-knowledge' (see Cassam 1994). The term 'self-knowledge' is misleading in a number of different ways: we are not talking here about knowledge of the self, but of the special kind of epistemic access that we have our own states of mind, and events in our mind. Hence, the awareness we have of our own sensations and experiences is also a form of 'self-knowledge' in this sense. Also, it is questionable whether such awareness is itself knowledge, or whether it is simply something that makes knowledge possible. (Compare: is perception itself knowledge, or is it something that makes knowledge possible?) 
Nonetheless, these qualifications made, we can take 'self-knowledge' in the contemporary sense to be a term for the distinctive capacity to access one's own mind, as opposed to the access one has to the minds of others. In the first kind of case, of the capacity is exercised in coming to believe something (making up one's mind). In the second kind of case, it is exercised in our spontaneous access to what we believe anyway. And in the third kind of case, the capacity is exercised in our ability to introspect and examine our own beliefs.

But it is important to emphasise that not all thoughts (in my sense) are judgements. Consciously thinking something can be pursued without the desire to commit to the truth of any particular proposition thought. One could simply be considering something, without needing or wanting to make up one's mind. Such speculation takes place against a background of belief, of course; but not all of these beliefs need to be brought to mind in order for one to speculate.

Conscious thoughts, then, are episodes. My claim is that without employing the idea of a phenomenally conscious episode, it is not possible to make sense of what underlies the talk of 'conscious belief' or 'access (A) consciousness'. It is true that information could be used by a cognitive system, and hence 'accessed' even at the level of the information-processing in the brain. But there is no reason to call this kind of 'accessing' a kind of consciousness. The only point of saying that these states are A-conscious, as far as I can see, is to mark the fact that they can manifest themselves in consciousness. And the same applies to the talk of 'conscious belief'.

We are now in a position to answer the question with which I began this paper: are thoughts and sensations/sensory experiences conscious in the same way? Is there a single sense of 'conscious' in which all these otherwise very different mental phenomena are conscious? My answer is that they are conscious in the same way, because thoughts and sensory experiences are episodes or events in the 'stream' of a subject's consciousness. Of course, this is not a definition of the sense in which they are conscious, because it appeals to the idea of a stream of consciousness. But the image of the stream is supposed to tell us something significant about the structure of conscious phenomena. It is essential that thoughts or episodes of thinking, like sensations and sensory experiences, are occurrences: they are events or processes that have a particular temporal extent and duration. This is compatible with sensations and thoughts differing in all sorts of other ways (for example, in the extent to which it is intelligible to think of them as subject to constraints of reason or rationality). But 
what I have been arguing for here is the fundamental similarity between them, rather than any differences.

Finally, we have seen that the other thing sensations and conscious thoughts have in common is that they can both be known by the exercise of our capacity for self-knowledge - or, as I would prefer to say, they are both available to the subject through privileged access. Why this is, and what the exact connection is between nonconscious states of mind like beliefs and our capacity to know these states with privileged access, are questions which must be left to another occasion.

\section{Conclusion: phenomenal intentionality and conscious thought}

What are the implications of the answer to our question for the idea of phenomenal intentionality?

The first implication is that if we want to look for phenomenal intentionality outside the less controversial examples (e.g. perceptual experience), we should not be asking ourselves whether beliefs exhibit a phenomenal character of their own. If phenomenal character is the character of phenomenal episodes, and these are episodes in the stream of consciousness, then since beliefs are not episodes in the stream of consciousness, beliefs can never have phenomenal character. But thoughts - in the sense characterized in $\S 4$ above - do have phenomenal character, since they are episodes in the stream of consciousness.

The next question is whether thoughts have phenomenal character of their own: i.e. phenomenal character which is not the character of some other kind of episode. It is true that some thoughts are accompanied by imagery or words (talking to yourself, words running through your mind, images coming to you). But part of the phenomenal character of the experience is something that cannot be conveyed by these sensory or linguistic representations: it is the attitudinal component of the thought. Maybe the 'vehicle' of the content of a conscious thought is words running through your mind; but the attitude (judging, hoping, desiring etc) cannot be. There need be no words which correspond to the attitude when you judge that $p$ rather than manifest hope that $p$ : you do not have to verbally articulate your attitude in order for the thought to involve that attitude. To develop this argument properly would be the next stage in the defence of the thesis that conscious thoughts have a phenomenal intentionality to call their own. But the first stage is to get a correct view of the 
metaphysics, or apparent metaphysics, of phenomenal intentionality. This is what I have attempted to do here.

\section{References}

Audi, Robert (1994) 'Dispositional Belief and Dispositions to Believe' Nous 28: 41934

Bayne, Tim and Michelle Montague (2011) (eds.) Cognitive Phenomenology Oxford: Oxford University Press

Block, Ned (1996) 'Mental paint and mental latex' Philosophical Issues 7: 19-49

BonJour, Laurence (1999) 'The Dialectic of Foundationalism and Coherentism' in John Greco \& Ernest Sosa (eds.) Blackwell Guide to Epistemology Oxford: Blackwell

Carruthers, Peter (2003) Phenomenal Consciousness Cambridge: Cambridge University Press

Cassam, Quassim (1994) (ed.) Self-Knowledge Oxford: Oxford University Press

Crane, Tim (2001) Elements of Mind Oxford: Oxford University Press

Crane, Tim (forthcoming), 'Tye on Acquaintance and the Problem of Consciousness' Philosophy and Phenomenological Research 84: 190-98

Davidson, Donald (1967), 'Causal Relations' Journal of Philosophy 64: 691-703

Dretske, Fred and Palle Yourgrau (1983) 'Lost Knowledge', Journal of Philosophy Gennaro, Rocco J. (1996) Consciousness and Self-Consciousness: a Defense of the Higher-Order Thought Theory of Consciousness, Amsterdam John Benjamins Hill, Christopher (2009) Consciousness Cambridge: Cambridge University Press Kim, Jaegwon (1976) 'Events as Property Exemplifications' in Myles Brand and Douglas Walton (eds.) Action Theory Dordrecht: Reidel, 159-178

Kriegel, Uriah (2004) 'Moore's Paradox and the Structure of Conscious Belief' Erkenntnis 61: 99-121

Kriegel, Uriah (2007) 'Intentional Inexistence and Phenomenal Intentionality' Philosophical Perspectives 21: 307-340

Lewis, David (1986) 'Events' in Philosophical Papers, Volume II, Oxford: Oxford University Press, 241-269

Lycan, W.G. (2001) 'A Simple Argument for a Higher-Order Representation Theory of Consciousness' Analysis 61: 3-4 
McDowell, John (1994) Mind and World Cambridge, Mass.: Harvard University Press

McDowell, John. (2009), 'Avoiding the Myth of the Given' The Engaged Intellect (Cambridge, MA: Harvard University Press) 256-74

Mellor, D.H. (1981), Real Time Cambridge: Cambridge University Press

Oddie, Graham (2005) Value, Reality and Desire Oxford: Oxford University Press

Peacocke, Christopher (1993) A Study of Concepts, Cambridge, Mass.: MIT Press

Pitt, David (2004) 'The Phenomenology of Cognition Or What Is It Like to Think That P?' Philosophy and Phenomenological Research 69: 1-36

Rosenthal, David (1986) 'Two concepts of consciousness' Philosophical Studies 49: 329-359

Ruben, David-Hillel (2003) Action and its Explanation Oxford: Oxford University Press

Russell, Bertrand (1910-11) 'Knowledge by Acquaintance and Knowledge by Description' Proceedings of the Aristotelian Society XI: 108-28

Searle, John (1992) The Rediscovery of the Mind, Cambridge, Mass.: MIT Press

Soteriou, Matthew (2007) 'Content and the Stream of Consciousness' Philosophical Perspectives 21: 543-68

Strawson, Galen (1995) Mental Reality Cambridge, Mass.: MIT Press

WIlliamson, Timothy (2000) Knowledge and its Limits Oxford: Oxford University Press 